\title{
Robert Grunert, Der Europagedanke westeuropäischer faschistischer Bewegungen 1940-1945
}

Paderborn, Munich, Vienne, Zurich : Ferdinand Schöningh, 2012, 318 p., $44,90 €$

Heidi Knörzer

\section{OpenEdition}

\section{Journals}

Édition électronique

URL : http://journals.openedition.org/ifha/7706

DOI : $10.4000 /$ ifha. 7706

ISSN : 2198-8943

Éditeur

IFRA - Institut franco-allemand (sciences historiques et sociales)

Référence électronique

Heidi Knörzer, « Robert Grunert, Der Europagedanke westeuropäischer faschistischer Bewegungen

1940-1945 », Revue de l'IFHA [En ligne], Date de recension, mis en ligne le 15 décembre 2013, consulté le 22 septembre 2020. URL : http://journals.openedition.org/ifha/7706 ; DOI : https://doi.org/10.4000/ ifha.7706

Ce document a été généré automatiquement le 22 septembre 2020.

C)IFHA 


\section{Robert Grunert, Der Europagedanke westeuropäischer faschistischer Bewegungen 1940-1945}

Paderborn, Munich, Vienne, Zurich : Ferdinand Schöningh, 2012, 318 p., $44,90 €$

\section{Heidi Knörzer}

La victoire de l'Allemagne nazie sur les démocraties ouest-européennes en 1940 a mis les mouvements fascistes des pays occupés dans une situation délicate. Dans un premier temps, ces derniers ont certes salué cette victoire, espérant pouvoir prendre le pouvoir dans leur pays. Mais très vite, leurs espoirs ont été déçus. Non seulement les nazis ont préféré collaborer avec les élites conservatrices des pays occupés, mais leur politique n'a pas non plus conduit à la «révolution sociale» que les mouvements fascistes de ces pays avaient appelé de leurs vœux. Si, malgré ce contexte, les mouvements fascistes des pays occupés ont continué à voir dans l'Allemagne nazie un modèle, ils ont néanmoins développé d'autres positions, notamment en ce qui concerne le projet hitlérien de construire un "nouvel ordre» en Europe sous domination allemande que Birgit Kletzin a récemment décrit comme une "Europe de race et d'espace ».

Ce sont ces projets alternatifs d'une Europe fasciste qu'étudie l'ouvrage Der Europagedanke westeuropäischer faschistischer Bewegungen 1940-1945 de Robert Grunert à l'exemple des Pays Bas, de la Belgique et de la France. Si l'historiographie a déjà fait état des mouvements et partis fascistes de ces pays, la pensée européenne et "l'internationalisme » fascistes n'ont pas encore fait l'objet d'une étude approfondie. L'ouvrage de R. Grunert, qui reprend le contenu de sa thèse de doctorat, comble donc cette lacune importante.

Après une brève introduction, l'auteur rappelle dans le premier chapitre l'histoire de la genèse du Nationaal-Socialistische Beweging néerlandais, du Rex belge et du Parti Populaire Français. Dans le deuxième chapitre, il expose les représentations nazies de l'Europe. Les chapitres 4, 5 et 6 qui constituent le cœur de l'ouvrage, mettent en évidence que les 
conceptions de l'Europe, développées par les leaders fascistes néerlandais, belges et français, se distinguent à des degrés divers de celles d'Adolf Hitler, et même de celles d' Heinrich Himmler et d'une partie des leaders SS qui entendaient accorder un statut privilégié aux "peuples germaniques» au sein d'une Europe sous hégémonie allemande.

Ainsi, Anton Adriaan Mussert, le leader du Nationaal-Socialistische Beweging, voulait créer " une confédération d'Etats germaniques », constituée du Reich allemand, des Pays-Bas, de la Flandre et des régions flamandes du Nord de la France et basée sur une politique sociale ainsi que sur une armée communes. Par la création d'une telle confédération, il espérait pouvoir sauver l'Europe du «capitalisme anglo-américain» et du «bolchévisme asiatique». S'il adhérait aux projets de déplacement forcé de populations pour éviter les mélanges et qu'il soutenait la déportation des juifs, Mussert s'opposait cependant à l'idéologie raciale des nazis et à une domination allemande au sein de cette confédération. Ajoutons qu'il n'hésitait pas à critiquer ouvertement l'exploitation des Pays-Bas par l'occupant allemand. L'Europe des représentants du rexisme belge comme Léon Degrelle ou José Streel ressemblait à bien des égards à celle de Mussert. Ils rêvaient en effet d'une « union fraternelle » de toutes «les révolutions nationales" en Europe afin de former un espace économique commun. Si ces conceptions entraient en conflit avec celles des nazis, notamment en ce qu'elles s'appuyaient sur une participation égalitaire de tous les pays membres, les fascistes français favorisaient «la collaboration inconditionnelle» avec l'Allemagne hitlérienne. Jacques Doriot, le fondateur du Parti Populaire Français, était même prêt à renoncer définitivement à l'Alsace-Lorraine, espérant ainsi pouvoir jouer, à côté de l'Allemagne, un rôle de leader politique dans la « Nouvelle Europe » fasciste.

Se basant sur de nombreuses sources d'archives, R. Grunert nous livre ici un travail de pionnier dont la lecture est très éclairante pour comprendre les conceptions de l'Europe élaborées par les mouvements fascistes des pays occupés. L'étude montre notamment à quel point ces idées qui très heureusement n'ont pas réussi à s'imposer, ont été discutées amplement, bien plus que le nationalisme exacerbé des mouvements fascistes aurait voulu laisser croire. En analysant les rapports des mouvements fascistes des pays occupés avec les nazis, l'ouvrage contribue également à la construction d'une typologie du fascisme.

\section{INDEX}

Index chronologique : Neuere und Neueste Geschichte Thèmes : Politische Geschichte 
AUTEUR

HEIDI KNÖRZER

École Polytechnique 